\title{
The Microwave Spectrum and Structure of the Furan. Sulfur Dioxide Complex
}

\author{
Jung JiN OH, LI-Wei Xu, Amine Taleb-Bendiab, Kurt W. Hillig II, \\ AND ROBERT L. KUCZKOWSKI \\ Department of Chemistry, University of Michigan, Ann Arbor, Michigan $48109-1055$
}

\begin{abstract}
The microwave spectrum of furan - sulfur dioxide complex has been observed with a pulsed molecular beam Fourier transform microwave spectrometer. Transitions having $a-b$, and $c$ dipole selection rules were all seen. The rotational constants of the normal isotopic species are $A$ $=3190.7285(11), B=1119.3596(2)$, and $C=1015.6841$ (2) $\mathrm{MHz}$. In addition, the rotational spectra of the $\mathrm{C}_{4} \mathrm{H}_{4} \mathrm{O} \cdot{ }^{34} \mathrm{SO}_{2}, \mathrm{C}_{4} \mathrm{H}_{4} \mathrm{O} \cdot \mathrm{S}^{18} \mathrm{O}_{2}, \mathrm{C}_{4} \mathrm{D}_{4} \mathrm{O} \cdot \mathrm{SO}_{2}$, and two different $\mathrm{C}_{4} \mathrm{H}_{4} \mathrm{O} \cdot \mathrm{SO}{ }^{18} \mathrm{O}$ isotopic species were assigned. Stark effect measurements gave dipole moment components of $\mu_{a}=$ $1.79(1) \mathrm{D}, \mu_{b}=0.50(2) \mathrm{D}, \mu_{c}=0.73(1) \mathrm{D}$, and $\mu_{\text {toral }}=1.99$ (2) $\mathrm{D}$. The moment of inertia data show that the two monomers are separated by $3.43(1) \AA\left(R_{\mathrm{cm}}\right)$, with the $\mathrm{SO}_{2}$ lying above the furan plane. The two $C_{2}$ axes of the monomer units are skewed by about $65^{\circ}$ and the plane of the $\mathrm{SO}_{2}$ is tipped considerably from parallel to the furan plane, with the sulfur atom closest to the furan. While one oxygen in $\mathrm{SO}_{2}$ lies approximately above the oxygen of the furan, the other is located closer to a $\beta$-carbon of the furan. Splittings of the $c$-dipole transitions for various isotopes suggest a tunneling motion between two equivalent forms of the complex. 1992 Academic Press. Inc.
\end{abstract}

\section{INTRODUCTION}

Sulfur dioxide exhibits a variety of structural arrangements in forming complexes with Brönsted acids, $\pi$ donors, and nitrogen and oxygen lone pairs in Lewis bases. In transition metal complexes, two common interactions are the $\eta_{1}$ pyramidal and $\eta_{2}$ two center types (1). The former is characterized by attachment of the transition metal through sulfur, with the $\mathrm{SO}_{2}$ plane tipped away from coplanar with the metalsulfur linkage. In the $\eta_{2}$ mode, an S-O bond interacts with the metal center forming a triangular $M-\mathrm{S}-\mathrm{O}$ arrangement. Brönsted acids such as $\mathrm{HF}$ and $\mathrm{HCl}$ are known to bond through one of the oxygen lone pairs forming a planar complex (2). Benzene $\cdot \mathrm{SO}_{2}$ is a prototype $\pi$ complex, which has been known for some time (3). Recently it was shown that the benzene and $\mathrm{SO}_{2}$ planes have a stacked arrangement $(4 a)$. The $\mathrm{SO}_{2}$ plane is tipped slightly from parallel to the benzene plane so that the sulfur end is closer to the benzene $\pi$ cloud. In the trimethylamine $\cdot \mathrm{SO}_{2}(5,6)$ and pyridine $\cdot \mathrm{SO}_{2}$ (4) complex the nitrogen lone pair is directed to a nearly perpendicular $\mathrm{SO}_{2}$ plane, at the sulfur end, forming an $n$ (donor) $-\pi^{*}$ (acceptor) charge transfer complex.

The contrast between the benzene $\cdot \mathrm{SO}_{2}$ and pyridine $\cdot \mathrm{SO}_{2}$ complexes can be rationalized by simple explanations focusing on the polarities of benzene and pyridine or the differences in basicity of an aromatic- $\pi$ cloud vs a nitrogen lone pair when interacting with the $\mathrm{SO}_{2}$ acceptor. Furan is another simple heterocycle with both aromatic properties and a Lewis electron pair center. In this case the oxygen is considerably less basic than the nitrogen in pyridine. Nevertheless, the furan $\cdot \mathrm{HCl}$ complex is planar with a hydrogen bond formed to the oxygen (7). This is in contrast to benzene $\cdot \mathbf{H C l}$, where the $\mathrm{HCl}$ is perpendicular to the benzene plane and forms a hydrogen bond to 
TABLE I

Observed Transition Frequencies for Furan $\cdot \mathrm{SO}_{2}$

\begin{tabular}{|c|c|c|c|c|c|}
\hline \multirow{2}{*}{\multicolumn{2}{|c|}{ 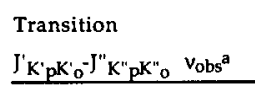 }} & \multirow{3}{*}{$\frac{\Delta v^{b}}{-1}$} & \multirow{2}{*}{\multicolumn{2}{|c|}{ 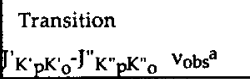 }} & \multirow{3}{*}{$\frac{\Delta v^{\mathrm{b}}}{0}$} \\
\hline & & & & & \\
\hline $3_{12}-2_{02}$ & 8840.553 & & $5_{05}-4_{04}$ & 10600.227 & \\
\hline $4_{13}-3_{03}$ & 11190.003 & 1 & $515-414$ & 10399.727 & 0 \\
\hline $5_{14}-4_{04}$ & 13603.963 & 0 & $5_{14}-4_{13}$ & 10916.186 & 1 \\
\hline $220-1_{10}$ & 10591.599 & 0 & $5_{24}-4_{23}$ & 10666.012 & 1 \\
\hline $221-I_{11}$ & 10691.478 & 0 & $5_{23}-4_{22}$ & 10740.416 & 0 \\
\hline $3_{21}-2_{11}$ & 12637.945 & 0 & $5_{33}-4_{32}$ & 10686.400 & 1 \\
\hline \multirow[t]{2}{*}{$3_{22}-212$} & 12930.016 & 0 & $5_{32}-431$ & 10688.221 & 0 \\
\hline & & & $5_{42}-441$ & 10682.396 & 6 \\
\hline $3_{13}-2_{02}$ & 8218.616 & 0 & $541-440$ & 10682.398 & -5 \\
\hline $322-2_{11}$ & 12618.999 & 1 & $606+505$ & 12681.712 & -2 \\
\hline $3_{21}-212$ & 12948.964 & 0 & $6_{16}-5_{15}$ & 12470.238 & 0 \\
\hline $221-1_{10}$ & 10587.804 & 1 & $615-5_{14}$ & 13087.280 & -1 \\
\hline $220-1_{11}$ & 10695.274 & 0 & $625-5_{24}$ & 12791.952 & 1 \\
\hline $4_{14}-3_{03}$ & 10153.934 & 0 & $6_{24}-5_{23}$ & 12919.448 & 1 \\
\hline $5_{05}-4_{14}$ & 8948.516 & -2 & $634-533$ & 12827.285 & -2 \\
\hline $5_{15}-4_{04}$ & 12051.435 & -1 & $6_{33}-5_{32}$ & 12832.128 & -1 \\
\hline $6_{16}-5_{05}$ & 13921.448 & 1 & $6_{43}-5_{42}$ & 12821.325 & 10 \\
\hline \multirow[t]{2}{*}{$606-5_{15}$} & 11230.506 & 2 & $6_{42}-5_{41}$ & 12821.368 & -7 \\
\hline & & & $7_{07}-6_{06}$ & 14746.095 & 0 \\
\hline $404-3_{03}$ & 8502.225 & 0 & $7_{17}-6_{16}$ & 14536.321 & 0 \\
\hline $4_{14}-3_{13}$ & 8325.174 & 0 & $7_{16}-6_{15}$ & 15250.949 & 0 \\
\hline $4_{13}-3_{12}$ & 8739.305 & -1 & $7_{26}-6_{25}$ & 14913.960 & 0 \\
\hline $423-322$ & 8536.777 & 0 & $725-624$ & 15111.396 & 0 \\
\hline $422-321$ & 8574.431 & 2 & $735-634$ & 14969.426 & 1 \\
\hline $432-3_{31}$ & 8546.908 & -3 & $734-633$ & 14980.259 & 2 \\
\hline \multirow[t]{2}{*}{$431-330$} & 8547.424 & 1 & $7_{44}-6_{43}$ & 14961.544 & -1 \\
\hline & & & $743-642$ & 14961.741 & -2 \\
\hline
\end{tabular}

the $\pi$ cloud (8). The only other structural information available for a weak complex of furan involves the furan - Ar van der Waals complex (9). In this species, the argon sits over the furan plane, similar to the pyridine $\cdot \operatorname{Ar}(10)$ and benzene $\cdot$ rare gas (11) complexes. These comparisons, and an interest in studying simple systems which can shed light on the properties of monomers which affect the structures of weakly bound complexes, prompted us to investigate the furan $\cdot \mathrm{SO}_{2}$ complex. We have found that it resembles benzene $\cdot \mathrm{SO}_{2}$; however, it possesses an unexpected and interesting asymmetry somewhat suggestive of the $\eta_{2}$ bonding mode formed in transition metal complexes.

\section{EXPERIMENTAL DETAILS}

Materials. A gas mixture containing $1 \%$ each of furan (Aldrich) and $\mathrm{SO}_{2}$ (Matheson) seeded in argon carrier gas was used to form the complex in a supersonic expansion. The enriched $\mathrm{C}_{4} \mathrm{D}_{4} \mathrm{O}$ sample (95\% deuterium, MSD Isotopes) was used without dilution with $\mathrm{C}_{4} \mathrm{H}_{4} \mathrm{O}$. The $\mathrm{S}^{18} \mathrm{O}_{2}$ transitions were observed using enriched $\mathrm{S}^{18} \mathrm{O}_{2}\left(99 \%{ }^{18} \mathrm{O}\right.$, Alfa Inorganics). The $\mathrm{S}^{16} \mathrm{O}^{18} \mathrm{O}$ sample was obtained by first mixing equal amounts of $\mathrm{SO}_{2}$ and $\mathrm{S}^{18} \mathrm{O}_{2}$ in a glass bulb, where they quickly equilibrated. The spectrum of the ${ }^{34} \mathrm{~S}$ isotopic species was observed in its natural abundance of $4 \%$.

Spectrometer. The FTMW spectrometer (12) operated in the region of 7.0 to 18 $\mathrm{GHz}$. The system has been described previously (13). A modified Bosch fuel injector 
TABLE II

Splittings Observed in the $b$ - and $c$-Dipole Transitions for the Isotopic Species of $\mathrm{C}_{4} \mathrm{H}_{4} \mathrm{O} \cdot \mathrm{SO}_{2}$ Complex

\begin{tabular}{|c|c|c|c|}
\hline 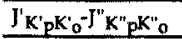 & $v_{1}^{a}$ & $v_{2}{ }^{a}$ & $\Delta v^{b}$ \\
\hline \multicolumn{4}{|l|}{$\mathrm{C}_{4} \mathrm{H}_{4} \mathrm{O}-\mathrm{SO}_{2}$} \\
\hline $3_{1,2}-20,2$ & 8840.513 & 8840.598 & 85 \\
\hline $41,3-30,3$ & 11189.962 & 11190.043 & 81 \\
\hline $5_{1,4}-40,4$ & 13603.923 & 13604.003 & 80 \\
\hline $22,0-11,0$ & 10591.585 & 10591.613 & $28^{c}$ \\
\hline $22,1-11,2$ & 10691.464 & 10691.491 & $27 \%$ \\
\hline $3_{2,1}-21,1$ & 12637.930 & 12637.960 & $30^{\mathrm{c}}$ \\
\hline $32,2-21,2$ & 12930.001 & 12930030 & $29 \mathrm{c}$ \\
\hline $32,2-2,1,1$ & 12618.980 & 12619.018 & 38 \\
\hline $3,1-2,2$ & 12948.940 & 12948.980 & 40 \\
\hline $22,1-11,0$ & 10587.783 & 10587.824 & 41 \\
\hline $2,0-11,1$ & 10695.251 & 10695.296 & 45 \\
\hline \multicolumn{4}{|l|}{$\mathrm{C}_{4} \mathrm{H}_{4} \mathrm{O} \cdot \mathrm{SO}^{18} \mathrm{O}(\mathrm{A})^{d}$} \\
\hline $31,2-20,2$ & 8685.364 & 8685.426 & 58 \\
\hline $41,3-30,3$ & 11000.476 & 11000.536 & 60 \\
\hline \multicolumn{4}{|l|}{$\mathrm{C}_{4} \mathrm{H}_{4} \mathrm{O} \cdot \mathrm{SO}^{18} \mathrm{O}(\mathrm{B})^{\mathrm{d}}$} \\
\hline $3_{1,2}-20,2$ & 8682.670 & 8682.706 & $36^{c}$ \\
\hline \multirow{2}{*}{$\begin{array}{l}4_{1,3}-30,3 \\
\mathrm{C}_{4} \mathrm{H}_{4} \mathrm{O} \cdot \mathrm{S}^{18 \mathrm{O}_{2}}\end{array}$} & 10992.721 & 10992.751 & $30 \%$ \\
\hline & & & \\
\hline $3_{1,2}-20,2$ & 8538.138 & 8538.179 & $41^{\mathrm{c}}$ \\
\hline $41,3-3_{0,3}$ & 10812.480 & 10812.515 & $35^{\mathrm{c}}$ \\
\hline $5,, 4-40,4$ & 13160.347 & 13160.408 & $61 \mathrm{c}$ \\
\hline $\begin{array}{l}\text { Observed trans } \\
\text { b } \Delta v=v_{2}-v_{1} \text { in l } \\
\text { c Uncertainties o } \\
\text { and weak inter } \\
\text { d See Fig. } 1 \text { for a }\end{array}$ & $\begin{array}{l}\text { frequency } \\
\text { s. } 5-10 k \\
\text { abeling. }\end{array}$ & estimated & Doppler effect \\
\hline
\end{tabular}

pulsed nozzle (BOS 0280-150-045) was used to generate a molecular beam with a repetition rate of about $23 \mathrm{~Hz}$. The nozzle orifice was $1.0 \mathrm{~mm}$ and the backing pressure of Ar was 1 to $2 \mathrm{~atm}$. Timing of the gas and microwave pulses was coordinated to minimize Doppler splitting of the transitions. Typical linewidths of $\sim 20 \mathrm{kHz}$ (FWHM) were observed unless deuterium quadrupole coupling or a tunneling motion (see below) broadened the transitions. Center frequencies were usually reproducible to $\pm 2 \mathrm{kHz}$ and accuracies are estimated to be $\pm 2 \mathrm{kHz}$.

To determine the dipole moment, $\mathrm{dc}$ voltages of up to $\pm 5 \mathrm{kV}$ were applied with opposite polarities to two steel mesh parallel plates $30 \mathrm{~cm}$ apart straddling the microwave cavity (13a). At each voltage, a Stark-shifted transition of the complex and of $\mathrm{SO}_{2}\left(2_{02}-1_{11}, M_{j}=0\right.$ component $)(14)$ were measured sequentially. In order to select transitions for which second-order perturbation theory was adequate, each component was examined to eliminate transitions which did not vary strictly with the square of the electric field $\left(E^{2}\right)$.

\section{RESULTS AND ANALYSIS}

Spectra. The normal isotopic species, with asymmetry parameter $\kappa=-0.904665$, had a near-prolate asymmetric top spectrum. Thirty-four $a$-dipole, ten $b$-dipole, and seven $c$-dipole transitions were assigned. Although the spectrum followed a semirigid asymmetric rotor pattern, all of the $c$-dipole transitions were split by $30-80 \mathrm{kHz}$; several $b$-dipole transitions also showed splittings of about $40 \mathrm{kHz}$ due to the tunneling motion (see later section). No obvious intensity alternations were seen between the two components of the doublets. As the observed splittings were small, the first attempts 
TABLE III

Observed Transition Frequencies for the Isotopic Species of $\mathrm{C}_{4} \mathrm{H}_{4} \mathrm{O} \cdot \mathrm{SO}_{2}$

\begin{tabular}{|c|c|c|c|c|c|c|c|c|c|c|}
\hline Transition & $34 \mathrm{c}$ & & $18 \mathrm{O} A$ & & $18 \mathrm{OCB}$ & & $18 \mathrm{O}_{2}$ & & $\mathrm{D}_{4}$ & \\
\hline 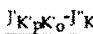 & $V^{\prime \prime} k_{0}^{\circ} v_{o b s}{ }^{a}$ & $\Delta x$ & $v_{\text {obs }}$ & $\Delta v$ & $y_{\text {obs }}$ & $\Delta v$ & $v_{\text {obs }}$ & $\Delta v$ & Vobs & $\Delta v$ \\
\hline $312=202$ & & & 8685.395 & -2 & 8682.688 & 3 & 8533.159 & 1 & & \\
\hline & & & 11000.506 & -2 & 10992.736 & -2 & 10812,498 & -1 & & \\
\hline $4-404$ & & & & & 13160.378 & 0 & & & & \\
\hline $14-303$ & & & & & 9940.866 & 1 & & & & \\
\hline $15-404$ & & & 11788.145 & -3 & 11792.557 & -1 & & & & \\
\hline $15-414$ & & & & & 8770.232 & 1 & & & & \\
\hline 05 & & & 13612.771 & 3 & & & & & & \\
\hline 303 & 8420.968 & $a$ & 8337.428 & 0 & 8328.832 & 0 & 8174,665 & 0 & 8147.525 & -1 \\
\hline 313 & & -1 & 8157.057 & 0 & 8150.042 & 0 & 7992.190 & -1 & & - \\
\hline 12 & 8651.713 & 1 & 8582.346 & 1 & 8570.470 & -1 & 8425.273 & 0 & 8358.054 & -2 \\
\hline $23-322$ & & & 8374.597 & 0 & 8365.022 & 1 & 8213.914 & 0 & 8179. & 3 \\
\hline $22-321$ & & & 8415.088 & 0 & & & 8256.657 & -1 & 8213.531 & 6 \\
\hline $05-404$ & 10499.958 & 0 & 10392.267 & 1 & 10382.264 & 1 & 10187.269 & 2 & 10159.284 & 0 \\
\hline $15-414$ & 103 & -3 & 10189.320 & l & 10180.526 & I & 9982.671 & -1 & 998 & -1 \\
\hline $14-4_{13}$ & 10807.098 & $\frac{4}{2}$ & 10719.374 & 0 & 10704.762 & -1 & 10522.544 & 0 & & -1 \\
\hline $24-423$ & & & 932 & -1 & 10451.095 & -2 & 10261.799 & 1 & & -5 \\
\hline $3-422$ & & & 10542.852 & +1 & 10528.939 & 0 & 10346.084 & 0 & & 2 \\
\hline & & & & & 10472.444 & -1 & 10284.934 & 1 & & \\
\hline $5_{32}-431$ & & & & & 10474.414 & 0 & 10287.183 & 0 & & \\
\hline-505 & 12563.131 & 0 & 12429.595 & 0 & 12418.565 & -1 & .601 & -1 & 12156.094 & 1 \\
\hline $6-515$ & 123 & 3 & 12216.885 & -2 & 12206.812 & 1 & 11968.662 & 0 & & 3 \\
\hline $5-514$ & 12956.990 & -4 & 12850.149 & 1 & 12832.974 & -1 & 12613.180 & 1 & 12517.216 & o \\
\hline & & & 12547.741 & 0 & 12533.734 & 1 & 12305.970 & 0 & & \\
\hline $5_{23}$ & & & 12684.426 & 0 & 12666.952 & 0 & 12449.891 & 0 & 12372.869 & -4 \\
\hline & & & 12585.679 & 1 & 12570.697 & 0 & 12345.965 & 0 & & \\
\hline & & & 12591.134 & -1 & 12575.928 & 1 & 12351.940 & 0 & & \\
\hline 16 & & & 14449.031 & 0 & 14437.282 & -1 & 14157.483 & 0 & & -2 \\
\hline $17-616$ & & & & & 14228.515 & 0 & 13949.778 & 0 & 13955. & 2 \\
\hline $16-615$ & & & & & 14953.370 & 1 & 14695.259 & 0 & 14587,308 & 3 \\
\hline & & & & & & & 14345.716 & 1 & & \\
\hline $15-624$ & & & & & & & 14567.449 & 1 & & \\
\hline $735-634$ & & & & & & & 14408.325 & 1 & & \\
\hline $734-633$ & & & & & & & 14421.682 & 0 & & \\
\hline
\end{tabular}

a Observed frequency ( $v_{\text {obs }}$ ) in $\mathrm{MHz}$.

b $\Delta v=v_{0 b s}-v_{\text {calc }}$ in $\mathbf{k H z}$.

to fit the spectrum used a conventional Watson S-reduced Hamiltonian ( $I^{r}$ representation) (15) employing the average frequency of the two components. The observed and calculated frequencies are given in Table I. The observed splittings for the $b$-and $c$-dipole transitions are given in Table II. The small errors in the rotational constants which arise from the neglect of the splitting should have a negligible effect on the structural analysis. The origin of the splittings is discussed in a subsequent section. The spectra of the $\mathrm{C}_{4} \mathrm{H}_{4} \mathrm{O} \cdot{ }^{34} \mathrm{SO}_{2}, \mathrm{C}_{4} \mathrm{D}_{4} \mathrm{O} \cdot \mathrm{SO}_{2}, \mathrm{C}_{4} \mathrm{H}_{4} \mathrm{O} \cdot \mathrm{S}^{18} \mathrm{O}_{2}$, and two different $\mathrm{C}_{4} \mathrm{H}_{4} \mathrm{O} \cdot \mathrm{S}{ }^{18} \mathrm{OO}$, isotopic species have also been assigned. Their transition frequencies are listed in Tables II and III and the derived spectroscopic constants are given in Table IV.

Dipole moment. The electric dipole moment of the complex was determined by measurement of the frequency shift of the Stark components as a function of electric field. The second-order Stark effects $\left(\Delta \nu / E^{2}\right)$ for $10 M_{j}$ components from three transitions of the $\mathrm{C}_{4} \mathrm{H}_{4} \mathrm{O} \cdot \mathrm{SO}_{2}$ species were determined. A least-squares fit of $\Delta \nu / E^{2}$ using the calculated second-order coefficients gave the dipole components $\mu_{a}=1.785(8)$ $\mathrm{D}, \mu_{b}=0.496(19) \mathrm{D}, \mu_{c}=0.733(12) \mathrm{D}$, and $\mu_{\text {total }}=1.992(10) \mathrm{D}$. Many transitions showed some curvature due to near degeneracies, and only the components which were strictly linear (within $1 \%$ ) with the square of the electric field were included in this fit.

Structure. By analogy with pyridine $\cdot \mathrm{SO}_{2}(4)$, dimethylether $\cdot \mathrm{SO}_{2}(16)$, and $\mathrm{H}_{2} \mathrm{O} \cdot \mathrm{SO}_{2}(17)$, we expected $\mathrm{C}_{4} \mathrm{H}_{4} \mathrm{O} \cdot \mathrm{SO}_{2}$ to have an ac plane of symmetry. We thus initially searched for only $\mu_{a}$ and $\mu_{c}$ transitions. For a complex with an $a c$ symmetry 
TABLE IV

Spectroscopic Constants for the Isotopic Species of $\mathrm{C}_{4} \mathrm{H}_{4} \mathrm{O} \cdot \mathrm{SO}_{2}$

\begin{tabular}{|c|c|c|c|c|c|c|}
\hline & Normal & $34 \mathrm{~s}$ & ${ }^{18} \mathrm{O}(\mathrm{A})^{\mathrm{a}}$ & $18 O(B)^{a}$ & $18 \mathrm{O}_{2}$ & $\mathrm{C}_{4} \mathrm{D}_{4} \mathrm{O} \cdot \mathrm{SO}_{2}$ \\
\hline No. of linesb & 51 & 9 & 22 & 26 & 29 & 17 \\
\hline $\mathrm{A} / \mathrm{MHz}$ & $3190.7285(11)$ & $3187.054(280)$ & $3128.2733(8)$ & $3135.3030(6)$ & $3070.3865(10)$ & $2838.701(61)$ \\
\hline $\mathrm{B} / \mathrm{MHz}$ & $1119.3596(2)$ & $1107.749(1)$ & $1100.5163(2)$ & $1098.6984(1)$ & $1081.4327(1)$ & $1068.617(1)$ \\
\hline $\mathrm{C} / \mathrm{MHz}$ & $1015.6841(2)$ & $1006.517(1)$ & $994.0346(2)$ & $993.4374(1)$ & $972.9886(1)$ & $976.933(1)$ \\
\hline $\mathrm{P}_{\mathrm{bb}} / \mathrm{Amu} \mathrm{A}^{2}$ & 102.2378 & 102.2288 & 105.3719 & 104.9638 & 108.3416 & 111.2077 \\
\hline $\mathrm{D}_{\mathrm{j}} / \mathbf{k H z}$ & $1.20(1)$ & $1.19(1)$ & $1.15(1)$ & $1.16(1)$ & $1.12(1)$ & $1.07(1)$ \\
\hline$D_{T K} / \mathbf{k H z}$ & $4.13(1)$ & $3.49(90)$ & $3.98(1)$ & $3.91(1)$ & $3.82(1)$ & $3.37(10)$ \\
\hline $\mathrm{D}_{\mathrm{K}} / \mathbf{k H z}$ & $-4.17(23)$ & $-4.17 \mathrm{c}$ & $-4.17 \mathrm{c}$ & $-4.17 x$ & $-4.17 \mathrm{c}$ & $-4.1 \%$ \\
\hline $\mathrm{d}_{1} / \mathbf{k H z}$ & $-0.10(1)$ & $-0.10(1)^{c}$ & $-0.10(1)$ & $-0.10(1)$ & $-0.10(1)$ & $-0.08(1)$ \\
\hline $\mathrm{d}_{2} / \mathrm{kHz}$ & $0.03(1)$ & $0.03(\mathrm{I})^{\mathrm{C}}$ & $0.03(1)$ & $0.03(1)$ & $0.02(1)$ & $0.03(1)$ \\
\hline$\Delta v_{\mathrm{rms}} / \mathrm{kHz}$ & 2.4 & 3.3 & 1.3 & 1.3 & 0.8 & 3.3 \\
\hline
\end{tabular}

a See Figure 1 for atom labeling.

b Number of transitions used in the fit. Center frequencies were used for the inversion doublets.

c Fixed to the value for the normal isotope.

d $\Delta v=v_{\text {obs }}-v_{\text {calc }}$

plane, the moment of inertia $\left(I_{b}\right)$ and planar moments $\left(P_{b b}\right)$ of the complex are given by

$$
I_{b}(\text { complex })=I_{a}\left(\mathrm{SO}_{2}\right)+I_{b}(\text { furan })+\mu R_{\mathrm{cm}}^{2},
$$

and

$$
P_{b b}(\text { complex })=\sum_{i} m_{i} b_{i}^{2}=P_{a a}\left(\mathrm{SO}_{2}\right)+P_{b b}(\text { furan }),
$$

where $\mu$ is the reduced mass of the complex, i.e., $\left(M_{\mathrm{SO}_{2}} \cdot M_{\mathrm{C}_{4} \mathrm{H}_{4} \mathrm{O}}\right) /\left(M_{\mathrm{SO}_{2}}+\mathrm{M}_{\mathrm{C}_{4} \mathrm{H}_{4} \mathrm{O}}\right)$. The first isotopic species to be assigned were the normal, ${ }^{34} \mathrm{~S},{ }^{18} \mathrm{O}_{2}$, and one ${ }^{18} \mathrm{O}$ species. $P_{b b}$ is almost identical for the normal and ${ }^{34} \mathrm{~S}$ species (See Table IV), suggesting that the $\mathrm{S}$ atom lies in a symmetry plane. The increases in $P_{b b}$ for the ${ }^{18} \mathrm{O}(\mathrm{A})$ and ${ }^{18} \mathrm{O}_{2}$ species follow what was expected for one or two out-of-plane ${ }^{18} \mathrm{O}$ atoms. Assuming an $a c$ symmetry plane, two structures were found which fit these inertial data, differing in the sign of the tilt angle of furan. To resolve this ambiguity, the $\mathrm{C}_{4} \mathrm{D}_{4} \mathrm{O} \cdot \mathrm{SO}_{2}$ isotope was assigned. However, with the inclusion of this data, no structural model with a plane of symmetry could be found that fit the moments of inertia.

After exploring several possible causes for this discrepancy, we finally questioned the assumption that the structure was symmetric. We returned to the spectrometer and in short order assigned several $b$-dipole transitions as well as a second ${ }^{18} \mathrm{O}$ isotopic species, conclusively demonstrating that the structure of this complex has no symmetry. In retrospect we realized that because furan is an accidental near-symmetric top, it is difficult to determine the orientation of its $\mathrm{C}_{2}$ axis relative to the $\mathrm{SO}_{2}$ with data from only its normal isotopic species. The $\mathrm{C}_{4} \mathrm{D}_{4} \mathrm{O}$ species is sufficiently asymmetric to clearly resolve this ambiguity.

The determination of an asymmetric structure requires six parameters, assuming no structural change in each monomer structure $(18,19)$. These are the distance $\left(R_{\mathrm{cm}}\right)$, two tilt angles $(\alpha, \beta)$ of the $\mathrm{C}_{2}$ axes of each monomer with respect to $R_{\mathrm{cm}}$, two 


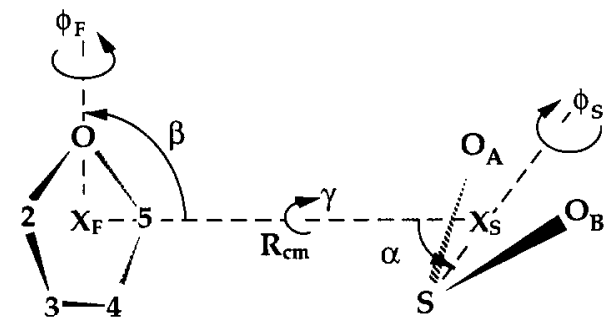

FIG. 1. Structural parameters employed in the analysis. $X_{F}$ and $X_{S}$ are the centers of mass of furan and $\mathrm{SO}_{2}$, respectively, and $R_{\mathrm{cm}}$ is the center-of-mass distance between them. Angle $\alpha$ is formed by the $\mathrm{C}_{2}$ axis of $\mathrm{SO}_{2}$ and $R_{\mathrm{cm}}$; angle $\beta$ is formed by the $\mathrm{C}_{2}$ axis of furan and $R_{\mathrm{cm}}$. Two wagging angles about these $\mathrm{C}_{2}$ axes are shown as $\phi_{\mathrm{F}}$ and $\phi_{\mathrm{S}}$ and can be defined as the dihedral angles $\phi_{\mathrm{F}}\left(\mathrm{C}_{2}-\mathrm{O}-\mathrm{X}_{\mathrm{F}}-\mathrm{X}_{\mathrm{S}}\right)$ and $\phi_{\mathrm{S}}\left(\mathrm{O}_{\mathrm{B}}-\mathrm{S}-\mathrm{X}_{\mathrm{S}}-\mathrm{X}_{\mathrm{F}}\right)$. The dihedral angle $\gamma\left(\mathrm{S}-\mathrm{X}_{\mathrm{S}}-\mathrm{X}_{\mathrm{F}}-\mathrm{O}\right)$ is formed between the $\mathrm{C}_{2}$ axes of furan and $\mathrm{SO}_{2}$. The signs of $\alpha$ and $\beta$ are positive as drawn. The signs of the dihedral angles are defined in Ref. (20).

rotation angles $\left(\phi_{\mathrm{S}}, \phi_{\mathrm{F}}\right)$ about the $\mathrm{C}_{2}$ axes of furan and $\mathrm{SO}_{2}$, and a torsional angle $(\gamma)$ about $R_{\mathrm{cm}}$. These parameters are defined in Fig. 1. The observed moments of inertia of the six isotopic species were least-squarcs fit to determine the six structural parameters.

\section{TABLE V}

Structural Parameters $\left(\AA ⿻\right.$ deg) for $\mathrm{C}_{4} \mathrm{H}_{4} \mathrm{O} \cdot \mathrm{SO}_{2}$

\begin{tabular}{|c|c|c|}
\hline & Structure I & Structure $\Pi^{a}$ \\
\hline \multicolumn{3}{|c|}{$\underline{\text { Fitted }}^{b}$} \\
\hline $\mathrm{R}_{\mathrm{cm}}$ & $3.432(1)$ & $3.433(1)$ \\
\hline$\alpha\left(<S-X_{S}-X_{F}\right)$ & $46.4(1.7)$ & $52.5(2.4)$ \\
\hline$\beta\left(<X_{S}-X_{F}-O_{F}\right)$ & $92.3(6)$ & $101.0(7)$ \\
\hline$\phi S\left(<O_{B}-S-X_{S}-X_{F}\right)^{c}$ & $-91.1(8)$ & $-93.5(1.0)$ \\
\hline$\phi_{\mathrm{F}}\left(<\mathrm{C}_{2}-\mathrm{O}_{\mathrm{F}}-\mathrm{X}_{\mathrm{F}}-\mathrm{X}_{\mathrm{S}}\right)$ & $-78.3(6)$ & $-98.2(1.1)$ \\
\hline$x\left(S-X_{S}-X_{F}-O_{F}\right)$ & $-117.3(2.7)$ & $+65.6(4.2)$ \\
\hline$\Delta \mathrm{I}_{\mathrm{rms}} \mathrm{b} / \mathrm{Amu} A^{2}$ & 0.204 & 0.293 \\
\hline \multicolumn{3}{|c|}{ Derivedd } \\
\hline$d\left(S-O_{F}\right)$ & $3.47(1)$ & $3.58(2)$ \\
\hline$d\left(S-C_{2}\right)$ & $3.28(2)$ & $3.52(2)$ \\
\hline$d\left(S-C_{3}\right)$ & $3.25(1)$ & $3.35(2)$ \\
\hline$d\left(S-C_{4}\right)$ & $3.44(2)$ & $3.26(2)$ \\
\hline$d\left(S-C_{5}\right)$ & $3.55(1)$ & $3.40(2)$ \\
\hline$<\mathrm{X}_{\mathrm{F}}-\mathrm{S}-\mathrm{O}_{\mathrm{A}}$ & $107.7(2.1)$ & $103.1(1.8)$ \\
\hline$<X_{F}-S-O_{B}$ & $109.2(2.4)$ & $108.4(1.9)$ \\
\hline$<S-X_{F}=O_{F}$ & $94.5(1.4)$ & $98.9(1.9)$ \\
\hline$d\left(O_{A}-O_{F}\right)$ & $3.73(2)$ & $4.50(2)$ \\
\hline $\mathrm{d}\left(\mathrm{O}_{\mathrm{A}}-\mathrm{C}_{2}\right)$ & $3.83(3)$ & $4.20(3)$ \\
\hline $\mathrm{d}\left(\mathrm{O}_{\mathrm{A}}-\mathrm{C}_{5}\right)$ & $4.07(2)$ & $4.06(4)$ \\
\hline$d\left(O_{A}-C_{3}\right)$ & $4.24(2)$ & $3.55(3)$ \\
\hline$d\left(O_{A}-C_{4}\right)$ & $4.39(2)$ & $3.44(4)$ \\
\hline $\mathrm{d}\left(\mathrm{O}_{\mathrm{B}}-\mathrm{O}_{\mathrm{F}}\right)$ & $4.38(2)$ & $4.00(3)$ \\
\hline $\mathrm{d}\left(\mathrm{O}_{8}-\mathrm{C}_{2}\right)$ & $3.74(3)$ & $4.39(3)$ \\
\hline$d\left(O_{B}-C_{5}\right)$ & $4.54(2)$ & $3.70(3)$ \\
\hline$d\left(O_{B}-C_{3}\right)$ & $3.51(2)$ & $4.39(2)$ \\
\hline$d\left(O_{B}-C_{4}\right)$ & $4.08(2)$ & $3.95(4)$ \\
\hline
\end{tabular}

a Structure II is preferred by the authors.

b Least-squares fit of the moments of inertia holding furan and $\mathrm{SO}_{2}$ geometries fixed [18,19]. See Figure 1 for definitions of parameters and atom labels. Standard deviation of the fit in parentheses. $\Delta \mathrm{I}=\mathrm{I}_{\text {exp }}-\mathrm{I}_{\text {calc }}$

c Sign follows convention in Ref. [20] for dihedral angles.

d Derived from the fitted structural parameters. 
TABLE VI

Principal Axes Coordinates $(\AA)$ for $\mathrm{C}_{4} \mathrm{H}_{4} \mathrm{O} \cdot \mathrm{SO}_{2}$ Structures I and II

\begin{tabular}{|c|c|c|c|c|c|c|}
\hline & \multicolumn{2}{|c|}{ a } & \multicolumn{2}{|c|}{$b$} & \multicolumn{2}{|c|}{$c$} \\
\hline & I & II & I & II & I & II \\
\hline$O_{A^{a}}$ & 1.978 & 1.959 & 1.294 & 1.211 & 0.133 & 0.227 \\
\hline $\mathrm{O}_{\mathrm{B}}$ & 2.072 & 2.041 & -1.172 & -1.256 & 0.234 & 0.173 \\
\hline$s$ & 1.508 & 1.535 & 0.021 & -0.026 & -0.320 & -0.354 \\
\hline$x_{s^{b}}$ & 1.767 & 1.767 & 0.041 & -0.024 & -0.068 & -0.077 \\
\hline$X_{F} c$ & -1.661 & -1.662 & -0.038 & 0.023 & 0.064 & 0.073 \\
\hline$O_{F}$ & -1.714 & -1.913 & 0.999 & -1.000 & 0.532 & -0.362 \\
\hline $\mathrm{C}_{2}$ & $-1,406$ & -1.921 & -0.177 & 0.202 & 1.166 & -1.022 \\
\hline $\mathrm{C}_{3}$ & -1.438 & -1.569 & -1.217 & 1.212 & 0.298 & -0.192 \\
\hline$C_{4}$ & -1.794 & -1.320 & -0.658 & 0.606 & -0.981 & 1.091 \\
\hline$C_{5}$ & -1.946 & -1.541 & 0.673 & -0.720 & 0.780 & 0.928 \\
\hline $\mathrm{H}_{2}$ & -1.194 & -2.196 & -0.093 & 0.155 & 2.215 & -2.060 \\
\hline $\mathrm{H}_{3}$ & -1.237 & -1.496 & -2.246 & 2.252 & 0.533 & -0.453 \\
\hline $\mathrm{H}_{4}$ & $-1,917$ & $-1,019$ & -1.177 & 1.092 & -1.914 & 2001 \\
\hline $\mathrm{H}_{5}$ & -2.204 & -1.486 & 1.496 & -1.568 & -1.420 & 1.584 \\
\hline
\end{tabular}

\footnotetext{
a See Fig. 1 for atom label definitions.

b Center of mass of $\mathrm{SO}_{2}$

c Center of mass of furan.
}

Two structures were found with similar values for $\Delta I_{\text {rms }}$, where $\Delta I=I_{\text {exp }}-I_{\text {calc }}$. The values for the six fitted parameters for both structures are given in Table $V$ and their principal axes coordinates are listed in Table VI. The values of $\alpha$ are around $50^{\circ}$, indicating a considerable tilt of the $\mathrm{SO}_{2}$ from perpendicular to $R_{\mathrm{cm}}$, with the sulfur closer to the furan. The values for $\beta$ are close to $90^{\circ}$, indicating that the furan plane is nearly perpendicular to $R_{\mathrm{cm}}$ in both structures. Since $\beta$ is actually larger than $90^{\circ}$, a small tilt of the oxygen end of furan away from the $\mathrm{SO}_{2}$ is suggested. The dihedral angles $\phi_{\mathrm{S}}$ and $\phi_{\mathrm{F}}$ deviate small amounts from $90^{\circ}$, indicating some twisting about the $\mathrm{C}_{2}$ axes of the $\mathrm{SO}_{2}$ and furan. These small deviations are in a direction (geared) which effectively rotates the $\mathrm{C}_{2}-\mathrm{C}_{3}$ edge in furan closer to the $\mathrm{SO}_{2}$ in Structure I but away in Structure II, while the $\mathrm{S}-\mathrm{O}_{\mathrm{A}}$ bond in $\mathrm{SO}_{2}$ is rotated slightly toward the furan. The dihedral angles $\gamma$ (absolute values) are approximately the supplement of each other, indicating that the major difference in the two structures is a rotation of the two moieties relative to each other by $180^{\circ}$. The top views in Figs. 2 and 3 illustrate this. In these views, the furan atoms have roughly the same magnitudes for the $b$ and $c$ coordinates for each structure, but opposite signs. The side views in Figs. 2 and 3 help to visualize the wagging ( $\phi_{\mathrm{S}}$ and $\phi_{\mathrm{F}}$ ) about the $\mathrm{C}_{2}$ axes.

These two structures are significantly different. Important differences are evident in the distance between atoms in $\mathrm{SO}_{2}$ and furan (Table V). For example, the oxygen in $\mathrm{SO}_{2}$, which is nearly over the furan oxygen, is closer in Structure I than Structure II ( 3.73 vs $4.00 \AA)$. The sulfur atom is also closer to the furan oxygen in Structure I

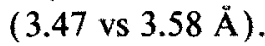

In an effort to choose between the two structures, the Kraitchman substitution coordinates $(21)$ were compared with values obtained from the least-squares fits. Also, the predicted dipole components using the values of free $\mathrm{SO}_{2}(14)$ and $\mathrm{C}_{4} \mathrm{H}_{4} \mathrm{O}(18)$ 

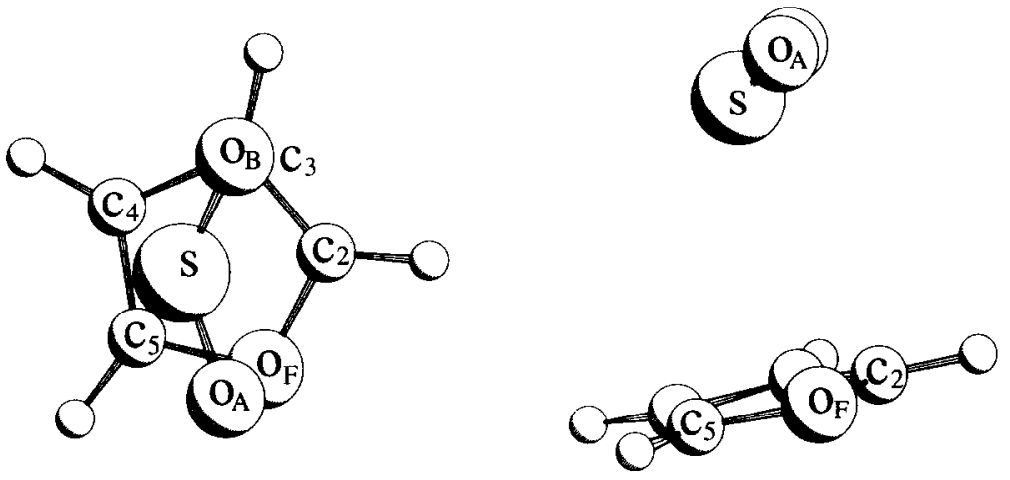

FIG. 2. Projection of Structure I from least squares fit in the $b c$ principal axis plane (left) and a side view projection (right) which is nearly an ac plane projection.

were examined for both structures. These are compared in Table VII. There is better agreement between the coordinates of Structure I. However, large amplitude motions contaminate the coordinate calculations and Structure II does not differ enough from the Kraitchman values to be conclusively eliminated. Regarding the dipole components, the large difference between the observed $\mu_{a}$ and the calculated values arises from polarization effects between the $\mathrm{SO}_{2}$ and furan. A similar large polarization along the $a$ axis is seen in other $\mathrm{SO}_{2}$ complexes, for example, ethylene $\cdot \mathrm{SO}_{2}(22)$. The small differences between $\mu_{b}$ are not helpful toward selecting the correct structure. However, the large value of $\mu_{c}$ predicted for Structure I, where the furan and $\mathrm{SO}_{2}$ dipoles are almost aligned, seems less attractive than the value for II. Nevertheless, polarization effects might be a factor here also and a firm preference for I or II cannot be expressed. This ambiguity is addressed by electrostatic energy calculations in the next section.

The structure of the $\mathrm{SO}_{2}$ calculated from the Kraitchman coordinates is $d\left(\mathrm{SO}_{A}\right)=$ $1.421 \AA, d\left(\mathrm{SO}_{B}\right)=1.404 \AA$, and $\angle \mathrm{OSO}=121.9^{\circ}$, which differs from the assumed structure in the least-squares fit of $1.431 \AA$ and $119.3^{\circ}$, respectively. These differences are common in such complexes and arise from the neglect of vibrational effects in the moments of inertia. It is unlikely that the $\mathrm{SO}_{2}$ structure is measurably perturbed in the complex.
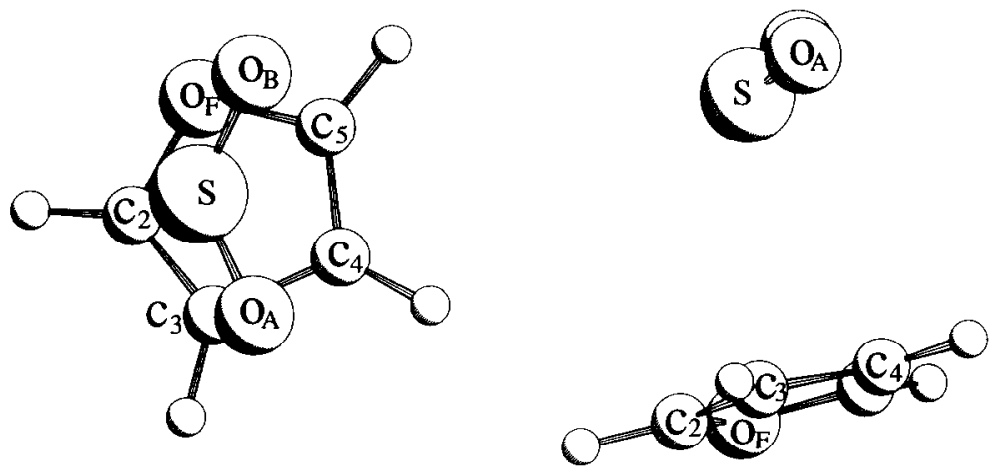

FIG. 3. Projection of Structure II from least-squares fit in the $b c$ principal axis plane (left) and a side view projection (right) which is nearly an ac plane projection. 
TABLE VII

Comparison of Observed Dipole Components and Kraitchman Coordinates with Predicted Dipole Components (D) and Oxygen Coordinates $(\bar{A})$ from Least-Square Fits

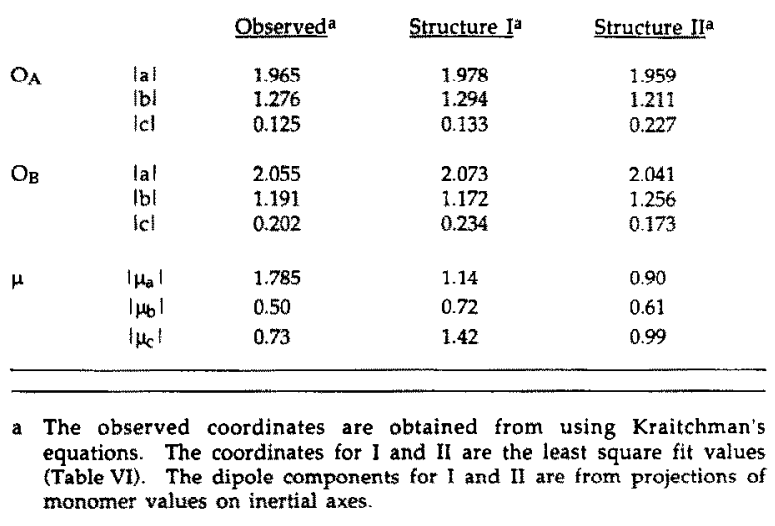

Electrostatic energy calculations. In an effort to choose a preferred structure, distributed multipole electrostatic energy calculations were examined. Buckingham and Fowler (23) have shown that such calculations predict the correct configuration for many weakly bound complexes, although detailed structural parameters may not be reliable. This model is based on an electrostatic interaction between each monomer using a set of distributed multipoles placed at each atom site in the monomers. A crude hard-sphere model for each atom accounts for the short-range repulsion. We have found this model to perform well for the $\mathrm{C}_{2} \mathrm{H}_{4} \cdot \mathrm{SO}_{2}$ complex (22). Application to $\left(\mathrm{SO}_{2}\right)_{2}$ resulted in a prediction of two isomers with nearly the same stabilization energies (24); one isomer resembled the experimental structure while no experimental evidence for the second predicted isomer has yet been obtained.

The distributed multipole moments were taken from the literature for $\mathrm{SO}_{2}(23 b)$ and were calculated for $\mathrm{C}_{4} \mathrm{H}_{4} \mathrm{O}$ with the CADPAC program (25) using the 6-31G** basis set. The values are given in Table VIII. Using these values, Structure II was predicted to have a stabilization energy of $-1.71 \mathrm{kcal} / \mathrm{mol} \mathrm{vs}-1.12 \mathrm{kcal} / \mathrm{mol}$ for Structure $\mathrm{I}$. The energy as a function of the dihedral angle $\gamma$ between furan and $\mathrm{SO}_{2}$ with all other parameters fixed are plotted in Fig. 4 for both structures. Structure II is consistently lower in energy than Structure I, and the predicted minimum for II is within $30-40^{\circ}$ of the observed value. For Structure $I$, the predicted minimum differs by about $100^{\circ}$ from the observed. As a check on the model, the minimum energy as a function of tilt angles of the $\mathrm{SO}_{2}(\alpha)$ and the furan $(\beta)$ were calculated holding the dihedral angle at the observed value for Structure II. These energy functions are illustrated in Fig. 5 and indicate that the model predicts values for $\alpha$ and $\beta$ within 5$30^{\circ}$ of the observed ones, lending some confidence in the parameterization.

In our opinion, these calculations cannot be considered conclusive evidence for Structure II over I. However, given the success of the model in other cases, the results are reasonably compelling and lead us to cautiously prefer Structure II until additional data may be forthcoming to question this choice.

Internal dynamics and distortion constants. The splittings observed for the $c$-dipole and several of the $b$-dipole transitions were somewhat unexpected due to the heavy 
TABLE VIII

Distributed Multipole Moments for $\mathrm{SO}_{2}$ and Furan (au $)^{\mathrm{a}}$

\begin{tabular}{|c|c|c|c|c|c|c|c|}
\hline & $q$ & $\mu_{x}$ & $\mu_{\mathrm{y}}$ & $\theta_{x x}$ & $\theta_{y x}$ & $\theta_{y y}$ & $\theta_{\mathrm{zz}}$ \\
\hline & & $y$ & & & $\mathrm{y}$ & & \\
\hline$S$ & 1.8060 & 0.0000 & -1.6280 & 1.3280 & 0.0000 & -1.2190 & -0.1090 \\
\hline OS & -0.5800 & -0.0310 & -0.0110 & 0.2730 & 0.3840 & -0.2210 & -0.0520 \\
\hline OF & -0.4637 & 0.0000 & -0.1905 & -0.4265 & 0.0000 & 0.0531 & 0.3734 \\
\hline $\mathrm{C}_{\alpha}$ & 0.2150 & -0.4006 & 0.3243 & 0.4838 & -0.6792 & -0.1356 & -0.3482 \\
\hline$C_{\beta}$ & -0.0906 & -0.1055 & -0.0448 & 0.1862 & 0.0578 & -0.0897 & -0.0965 \\
\hline $\mathrm{H}_{\alpha}$ & 0.0559 & 0.2033 & 0.1080 & -0.0619 & -0.0634 & 0.0209 & 0.0410 \\
\hline $\mathrm{H}_{\beta}$ & 0.0516 & 0.1370 & -0.1762 & -0.0037 & 0.0658 & -0.0366 & 0.0403 \\
\hline
\end{tabular}

$\mathrm{aSO}_{2}$ values from Ref. [23b]. Furan values calculated using CADPAC, Ref.

[25].

mass and the polar nature of the constituent monomers. These splittings for various isotopic species contain information on the tunneling motion.

We considered several possible pathways which exchange pairs of $\mathrm{CH}$ moieties, oxygen atoms, etc. One motion, the internal rotation of the furan about its own $\mathrm{C}_{2}$ axis, does not seem likely due to the fact that the hydrogen of the furan will move too close to the sulfur atom of $\mathrm{SO}_{2}$.

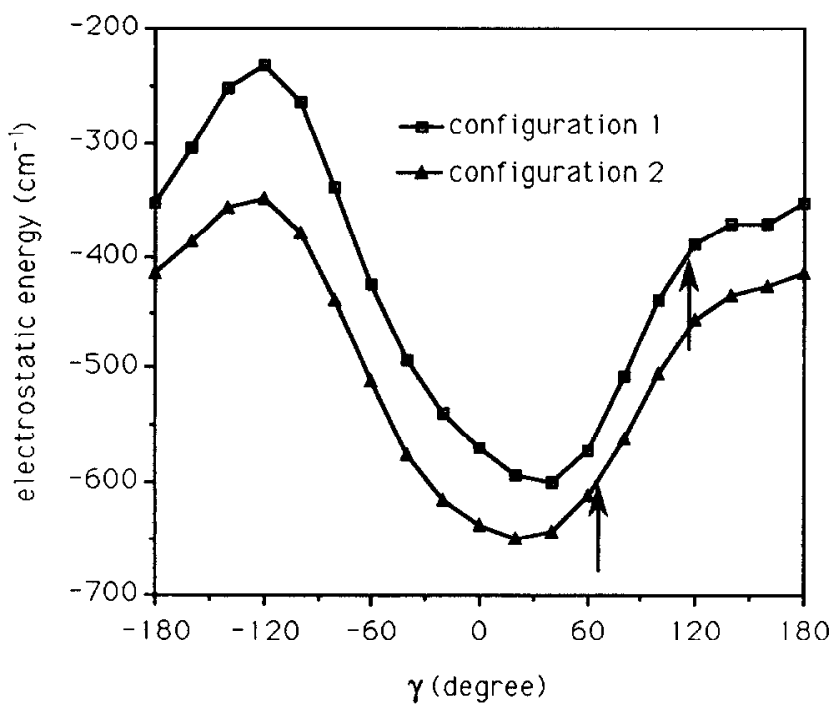

Fig. 4. Electrostatic energy vs dihedral angle $(\gamma)$ for Structures I and II. Note. For convenience in comparing the plots, the curve for Structure I is plotted for the mirror image of the form in Tables V and VI (reflection in the $b c$ plane). This changes the sign of the dihedral angle $(\gamma)$. The arrows designate the spectroscopic fitted value. 


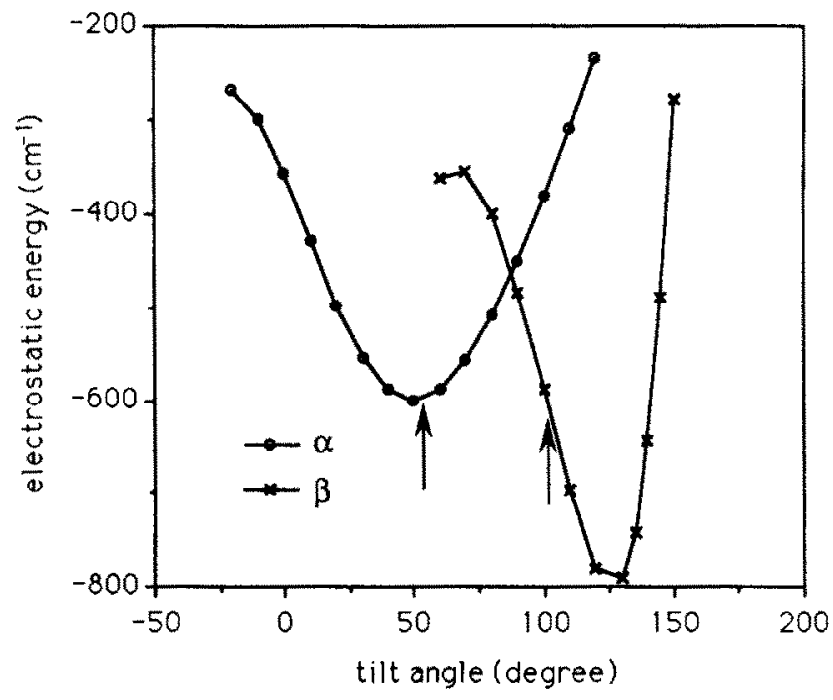

FIG. 5. Electrostatic energy vs $\mathrm{SO}_{2}$ and furan tilt angles ( $\alpha$ and $\beta$, respectively). $R_{\mathrm{sm}}, \phi_{\mathrm{s}}, \phi_{\mathrm{F}}$, and $\gamma$ fixed at Structure II values. The arrows designate the spectroscopic fitted values.

Some other possible motions are illustrated in Fig. 6. The labels II, III, IV are used to refer to the configurations after the tunneling motion. The nuclear spin statistics of $\mathrm{SO}_{2}$ rule out the possibility of the I $\rightarrow$ II motion, since for this motion one of the tunneling states will have spin weight zero. The I $\rightarrow$ III motion is eliminated, since it would not be expected to lead to closely spaced doublets for the two different single ${ }^{18} \mathrm{O}$ species. However, the I $\rightarrow$ IV motion can rationalize the splittings listed in Table II. This inversion may be pictured as a tunneling of the oxygen atoms on sulfur dioxide between two energetically equivalent positions on either side of the $C_{2}$ axis of the furan molecule. The exact pathway for the inversion motion is not known. However, it is interesting to speculate that the apparent attraction of the $\mathrm{SO}_{\mathrm{A}}$ bond with the $\mathrm{C}_{3-}$ $\mathrm{C}_{4}$ bond in Structure II (See Fig. 3) may influence the motion. Hence, the motion might be described as a rotation of the $\mathrm{SO}_{\mathrm{B}}$ bond about the $\mathrm{SO}_{\mathrm{A}}$ bond axis and an associated realignment of the $\mathrm{SO}_{\mathrm{A}}$ bond (and sulfur) relative to the furan. The different magnitudes of the splittings for the two distinct single ${ }^{18} \mathrm{O}$ isotopic species would appear to be consistent with this type of motion as the mass dependence upon substitution would be greater for $\mathrm{O}_{\mathrm{B}}$ than $\mathrm{O}_{\mathrm{A}}$. However, the splitting shows a noticeable $K$ dependence, indicating it is not a simple inversion motion with a constant spacing for all levels.

Interpretation of the distortion constants of asymmetric rotors is considerably more complex than for those of linear or symmetric-top molecules. For a complex with no symmetry, it is still more difficult to derive meaningful information. However, for weakly bonded dimers the largest contribution often arises from the new stretching mode between the two moieties. Commonly the pseudodiatomic approximation, which neglects contributions to the distortion constant $D_{J}$ from all vibrational modes except the stretching mode, is used to interpret the distortion constants (26). The expressions for $D_{J}$ are given in the monograph by Gordy and Cook (27):

$$
h \cdot D_{J}=-\hbar^{4}\left(3 \tau_{b b b b}+3 \tau_{c c c c}\right) / 8
$$




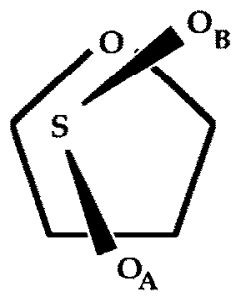

I

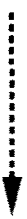

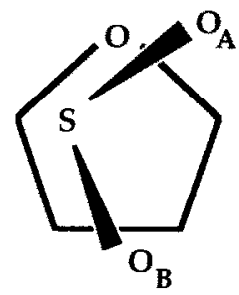

II

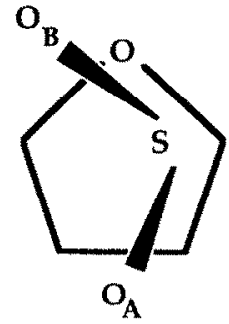

IV

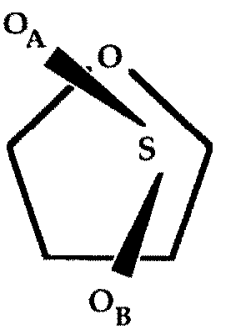

III

FIG. 6. Possible tunneling pathways to equivalent configurations for the furan $\cdot \mathrm{SO}_{2}$ complex.

The more fundamental $\tau_{\alpha \beta \gamma \delta}$ distortion constants were described originally by Kivelson and Wilson (28). These are related to the force constants $(f)$ and inertial derivatives $(J)$ of the complex in the following way:

$$
\tau_{\alpha \beta \gamma \delta}=-\frac{1}{2} \sum_{i j} J_{\alpha \beta}{ }^{(i)}\left(f^{-1}\right) i j J_{\gamma \delta}{ }^{(j)} .
$$

Using the above equations, the stretching force constant associated with the van der Waals stretching motion $\left(k_{\mathrm{s}}\right)$ along the $R_{\mathrm{cm}}$ coordinate has been estimated. Assuming that $\partial I_{b} / \partial R_{\mathrm{cm}} \approx 2 \mu R_{\mathrm{cm}}$, a value of $k_{\mathrm{s}}=0.073 \mathrm{mdyn} / \AA$ is obtained from $D_{J}$. The associated vibrational frequency is $\omega_{\mathrm{s}}=61.3 \mathrm{~cm}^{-1}$. Based on a ground state harmonic oscillator wave function, the vibrational amplitude is estimated to be $\sqrt{\Delta R_{\mathrm{cm}}^{2}}=$ $\sqrt{h \omega_{\mathrm{s}} / 4 \pi k_{\mathrm{s}}}=0.091 \AA$. Using a Lennard-Jones $6-12$ potential, the binding energy is about $1.72 \mathrm{Kcal} / \mathrm{mol}$. Due to the assumptions which have been made, $k_{\mathrm{s}}$ is accurate to probably no better than $\pm 10 \%$.

\section{DISCUSSION}

The structure of the furan $\cdot \mathrm{SO}_{2}$ complex mimics the benzene $\cdot \mathrm{SO}_{2}$ complex rather than the pyridine $\cdot \mathrm{SO}_{2}$ complex. The former is categorized as a $\pi$ (donor)- $\pi^{*}$ (acceptor) complex, while the latter involves an $n-\pi^{*}$ interaction. The LUMO of $\mathrm{SO}_{2}$ 
is a $\pi^{*}$ orbital with a large coefficient on the sulfur, which correlates with the tilted orientation of the $\mathrm{SO}_{2}$ and the placement of the sulfur end toward the donor's electrons. Since the lone pair of the oxygen in furan lies along its $\mathrm{C}_{2}$ axis, the location of $\mathrm{SO}_{2}$ above the plane of furan clearly signals that furan $\cdot \mathrm{SO}_{2}$ should be categorized as a $\pi$ $\pi^{*}$ complex. It is interesting that the orbital energies of the highest $\pi$ orbital and $n_{0}$ in furan ( 8.87 and $15.2 \mathrm{eV}$, respectively) correlate with this model but they do not in the case of pyridine $\left(\pi, 9.60 \mathrm{eV} ; n_{\mathrm{N}}, 10.51 \mathrm{eV}\right)(29)$. Although these chemical concepts may be useful for describing some complexes and their structures, it has been pointed out that the major attractive term in the interaction energy for such complexes is the electrostatic term. Polarization and charge transfer terms are smaller although they are often very important in the interpretation of the details of the interaction.

Given either of the two above models for describing the gross geometry of furan $\cdot \mathrm{SO}_{2}$, there are several details of the structure which are interesting. First, the tilt of $\mathrm{SO}_{2}$ plane which places the sulfur end closer to the furan plane seems reasonable. If the tilt angle of furan $\cdot \mathrm{SO}_{2}$ is converted to the angle between the $\mathrm{SO}_{2}$ plane and the molecular plane of furan a value of $63.5^{\circ}$ is obtained for Structure II. A smaller value is observed in ethylene $\cdot \mathrm{SO}_{2}\left(9^{\circ}\right)(22)$. In pyridine $\cdot \mathrm{SO}_{2}(4 b)$ and trimethylamine $\cdot \mathrm{SO}_{2}$ (6), the analogous angle between the $\mathrm{C}_{2}$ or $\mathrm{C}_{3}$ axis of the base and the $\mathrm{C}_{2}$ axis of the $\mathrm{SO}_{2}$ is $93^{\circ}$ and $100^{\circ}$, respectively.

A second feature which raises some curiosity is the twisting of the $\mathrm{SO}_{2}$ away from a symmetric alignment over the furan molecule. The $\mathrm{C}_{2}$ axis of $\mathrm{SO}_{2}$ is rotated roughly $65^{\circ}$ from the $\mathrm{C}_{2}$ axis of furan in the preferred Structure II. Thus the dipole moments of both monomers are more nearly antiparallel. In Structure I, they are more parallel and this may have some bearing on the difference in energy discussed above. However, the slight wagging of the $\mathrm{SO}_{2}$ and furan about their $\mathrm{C}_{2}$ axis (see Table $\mathrm{V}$ for the deviation of $\phi_{\mathrm{F}}$ and $\phi_{\mathrm{S}}$ from $90^{\circ}$ ) appears to be a crucial factor in the asymmetric alignment of $\mathrm{SO}_{2}$ relative to furan. If furan and $\mathrm{SO}_{2}$ do not wag, the electrostatic calculations indicate that the minimum energy will occur when the two $\mathrm{C}_{2}$ axes are aligned. This implies that the local electrical multipole moments in complex species like furan and $\mathrm{SO}_{2}$ (as parameterized by a distributed multipole moment configuration ) produce subtle interactions leading to asymmetric structures which will be difficult to anticipate by qualitative arguments.

A third intriguing observation is the tunneling motion which apparently involves a "rolling over" of the $\mathrm{SO}_{2}$ from one side of furan to the other. Although the details of the tunneling motion are not unambiguously established, the presence of a tunneling splitting is not without precedent in $\mathrm{SO}_{2}$ complexes. Tunneling motions have also been observed in the $\mathrm{Ar} \cdot \mathrm{SO}_{2}(30)$, ethylene $\cdot \mathrm{SO}_{2}(22)$, and $\mathrm{SO}_{2} \cdot \mathrm{SO}_{2}(24)$ systems. It is not possible to estimate a barrier height without more detailed insight on the tunneling pathway.

A thorough resolution and interpretation of these intriguing details probably requires a more detailed picture of the electrostatic interactions between furan and $\mathrm{SO}_{2}$ than explored in this paper. However, a simple distributed multipole model appears to be sufficient to qualitatively explain the asymmetric structure of the complex.

\section{ACKNOWLEDGMENT}

The authors are grateful to the donors of the Petroleum Research Fund, administered by the American Chemical Society, for support of this work. The research was also supported by the National Science Foundation, Washington, D.C. We are grateful for an allotment of computing time at the San Diego Supercomputing Center.

RECEIVED: January 13, 1992 


\section{REFERENCES}

1. R. R. Ryan, G. J. Kubas, D. C. Moody, and P. G. Eller, Struct. Bonding (Berlin) 46, 47-100 (1981).

2. (a) A. J. Fillery-Travis and A. C. Legon, Chem. Phys. Lett. 123, 4-8 (1986); (b) J. Chem. Phys. 85, 3180-3187 (1986).

3. L. J. ANDREWS AND R. M. KeEFER, J. Am. Chem. Soc. 73, 4169-4172 (1951).

4. (a) M. S. LABARGE, J.-J. OH, K. W. Hillig II, AND R. L. KuCZKowski, Chem. Phys. Lett. 159, 559562 (1989); (b) J.-J. OH, K. W. Hillig II, AND R. L. KuCzKowski, J. Am. Chem. Soc. 113, 7480$7484(1991)$.

5. D. Van Der Helm, J. D. Childs, and S. D. Christian, Chem. Commun. 887-888, (1969).

6. J.-J. OH, M. S. LaBarge, J. Matos, J. W. KampF, K. W. Hillig II, ANd R. L. KuCZKowski, J. $A m$. Chem. Soc. 113, 4732-4738 (1991).

7. (a) J. A. Shea And S. G. Kukolich, J. Chem. Phys. 78, 3545-3551 (1983); (b) J. Am. Chem. Soc. 104, 4999-5000 (1982).

8. (a) W. G. Read, E. J. Campbell, And G. Henderson, J. Chem. Phys. 78, 3501-3508 (1983); (b) W. G. Read, E. J. Campbell, G. Henderson, and W. H. Flygare, J. Am. Chem. Soc. 103, 7670$7672(1981)$.

9. (a) S. G. Kukolich, J. Am. Chem. Soc. 105, 2207-2210 (1983); (b) S. G. Kukolich ANd J. A. ShEA, J. Chem. Phys. 77, 5242-5243 (1982).

10. T. D. Klots, T. Emilsson, R. S. Ruoff, And H. S. Gutowsky, I. Chem. Phys. 93, 1255-1.261 (1989).

11. (a) R. E. Smalley, L. Wharton, and D. H. Levy, Acc. Chem. Res. 10, 139-145 (1977); (b) Th. Brupbacher and A. Bauder, Chem. Phys. Lett. 173, 435-438 (1990).

12. T. J. Balle AND W. H. Flygare, Rev. Sci. Instrum. 52, 33-45 (1981).

13. (a) R. K. Bohn, K. W. Hillig II, And R. L. KuCzkowski, J. Phys. Chem. 93, 3456-3459 (1989); (b) K. W. Hillig II, J. MAtos, A. Scioly, AND R. L. KuCzKowski, Chem. Phys. Lett. 133, 359$362(1987)$.

14. D. Patel, D. Margolese, and T. R. Dyke, J. Chem. Phys. 70, 2740-2747 (1979).

15. J. K. G. WatSON, J. Chem. Phys. 46, 1935-1949 (1967).

16. J.-J. OH, K. W. Hillig II, AND R. L. KUCZKOWSKI, Inorg. Chem. 30, 4583-4588 (1991).

17. K. Matsumura, F. J. Lovas, and R. D. Suenram, J. Chem. Phys. 91, 5887-5894 (1989).

18. P. Nösberger, A. Bauder, and Hs. H. Günihard, Chem. Phys. 1, 418-425 (1973).

19. M. D. Harmony, V. W. Laurie, R. L. Kuczkowski, R. H. Schwendeman, D. A. Ramsay, F. J. Lovas, W. J. Lafferty, AND A. G. Maki, J. Phys. Chem. Ref. Data 8, 619-721 (1979).

20. E. B. Wilson, JR., J. C. DECIUS, AND P. C. Cross, "Molecular Vibrations," Dover, New York, 1955.

21. J. Kraitchman, Am. J. Phys. 21, 17-24 (1953).

22. A. M. Andrews, A. Taleb-Bendiab, M. S. LaBarge, K. W. Hillig II, and R. L. Kuczkowski, $J$. Chem. Phys. 93, 7030-7040 (1990).

23. (a) A. D. Buckingham and P. W. Fowler, J. Chem. Phys. 79, 6426-6428 (1983); (b) Can. J. Chem. 63, 1918-1921 (1985).

24. A. Taleb-Bendiab, K. W. Hillig II, and R. L. Kuczkowski, J. Chem. Phys. 94, 6956-6963 (1991).

25. R. D. Amos AND J. E. RiCE, "Cambridge Analytical Derivatives Package, Issue 4.0," Cambridge, 1987.

26. D. J. Millen, Can. J. Chem. 63, 1477-1479 (1985).

27. W. Gordy AND R. L. Cook, "Microwave Molecular Spectra," 3rd ed., Wiley, New York, 1984.

28. D. Kivelson And E. B. Wilson, JR., J. Chem. Phys. 21, 1229-1236 (1953).

29. K. Kimura, S. Katsumata, Y. AChiba, T. Yamazaki, AND S. Iwata, "Handbook of HeI Photoelectron Spectra of Fundamental Organic Molecules," Halsted Press, New York, 1981.

30. R. L. Deleon, A. Yokozeki, And J. S. Muenter, J. Chem. Phys. 73, 2044-2048 (1986). 